\title{
Resistin aggravates the expression of proinflammatory cytokines in cerulein-stimulated AR42J pancreatic acinar cells
}

\author{
CHONG-YI JIANG and WEI WANG \\ Department of Surgery, Huadong Hospital, Fudan University, Shanghai 200040, P.R. China
}

Received November 17, 2015; Accepted November 14, 2016

DOI: $10.3892 / \mathrm{mmr} .2016 .6027$

\begin{abstract}
Resistin, an adipocytokine secreted by fat tissues, has been shown to be associated with increased local and systemic complications in acute pancreatitis (AP). However, the mechanism underlying the effect of resistin in the aggravation of AP remains to be elucidated. The aim of the present study was to investigate the functional consequences of exposing rat pancreatic acinar cells to resistin and to determine whether it amplifies proinflammatory signaling in an in vitro AP model. AR42J cells pretreated with recombinant resistin were activated by cerulein as an in vitro model of AP. The secretion of amylase was measured to evaluate the cytotoxic effect. The mRNA expression levels of tumor necrosis factor (TNF)- $\alpha$ and interleukin (IL)-6 were determined using reverse transcription-quantitative polymerase chain reaction analysis. The nuclear protein expression levels of the nuclear factor (NF)- $\kappa$ B p65 subunit were determined using western blot analysis. Resistin treatment significantly increased the secretion of amylase, and the mRNA expression levels of TNF- $\alpha$ and IL-6 in the cerulein-induced in vitro AP model. High protein levels of the NF- $\mathrm{B}$ p 65 subunit were observed in the nuclei of cells in the resistin-treated AP model, compared with the untreated AP model. Pretreatment of the in vitro resistin-treated AP model with the $\mathrm{NF}-\kappa \mathrm{B}$ inhibitor, pyrrolidine dithiocarbamate decreased the protein expression of the NF- $\kappa$ B p65 subunit in nuclei, and significantly attenuated the increased mRNA expression levels of TNF- $\alpha$ and IL-6 induced by resistin. The results of the present study showed that resistin increased the production of the TNF- $\alpha$ and IL- 6 proinflammatory cytokines via the NF- $\kappa \mathrm{B}$-dependent pathway during AP. Thus, the overproduction of obesity-associated resistin and the associated amplification of the inflammatory response may result in the aggravation of AP severity.
\end{abstract}

Correspondence to: Professor Wei Wang, Department of Surgery, Huadong Hospital, Fudan University, 221 Yanan West Road, Shanghai 200040, P.R. China

E-mail: jiangzhongyi9@hotmail.com

Key words: resistin, acute pancreatitis, proinflammatory cytokines, nuclear factor- $\kappa \mathrm{B}$

\section{Introduction}

The increasing incidence of obesity, leading to metabolic complications or metabolic syndrome, is now recognized as a major public health problem (1). Investigations have focused on the association between obesity and various chronic diseases; however, few studies have specifically defined its effect in acute inflammatory diseases (2). Previous studies have confirmed obesity as a negative prognostic factor in acute pancreatitis (AP) (3-5). Patients with AP who are obese have a higher rate systemic inflammatory response and poorer outcomes $(4,6)$. Meta-analysis has suggested that obesity is a risk factor for the development of local and systemic complications, and mortality rates in AP $(7,8)$. Novel scoring systems for the severity of AP have also been suggested, including obesity as an independent essential predictive factor (9).

Over the past decade, fat tissue has been viewed not only as a site of energy storage, but also as an active endocrine organ, which secretes a variety of bioactive substances known as adipocytokines (10). Adipocytokines have a wide variety of endocrine, paracrine and autocrine effects, including the regulation of energy metabolism, immunity and inflammation $(11,12)$. Resistin, a 108-amino-acid peptide hormone secreted by adipocytes and macrophages, is a member of the resistin-like molecule family of cysteine-rich proteins (13-15). Originally, resistin was implicated as a factor linking obesity and diabetes by impairing insulin sensitivity and glucose tolerance in mice (16). Elevated levels of resistin have been used as an early marker of inflammation in patients with AP due to its association with major local and systemic components of the inflammatory response (17). Resistin has also been shown to affect inflammatory cell infiltration of the pancreas and peripancreatic visceral fat tissues, thus affecting the severity of the clinical symptoms of AP $(18,19)$. Several previous studies have examined and characterized the association between resistin and inflammatory factors $(16,20-22)$ and have suggested that resistin may have an effect on the severity of AP.

It is generally considered that inflammation in AP is crucial in the pathogenesis of local and systemic damage (5). The activation of nuclear factor kappa B (NF- $\mathrm{kB}$ ), a transcription factor associated with the activation of inflammatory genes, results in the overexpression of inflammatory genes in pancreatic acinar cells (23). The ultimate severity of the resulting pancreatitis may be determined by the inflammatory responses, which occur subsequent to acinar cell injury (24). 
As resistin has potent immunomodulatory and metabolic activities (15), the present study hypothesized that the proinflammatory alterations observed in AP may be, in part, associated with the adipocytokine resistin.

In the present study, the effects of resistin were investigated on a cerulein-induced in vitro model of AP using the AR42J cell line. In addition, the mechanism underlying resistin-induced AP aggravation associated with $\mathrm{NF}-\kappa \mathrm{B}$ activation was determined using this model.

\section{Materials and methods}

Cell cultures. Rat AR42J pancreatic acinar cells were purchased from the China Center for Type Culture Collection (Wuhan, China). The AR42J cells were maintained in Ham's F-12 medium (Invitrogen; Thermo Fisher Scientific, Inc., Waltham, MA, USA) supplemented with $10 \%$ fetal bovine serum (Hangzhou Sijiqing Biological Engineering Materials Co., Ltd., Hangzhou, China), 100 U/ml penicillin and $100 \mu \mathrm{g} / \mathrm{ml}$ streptomycin. The cells were routinely plated at a density of $1 \times 10^{5}$ cells $/ \mathrm{ml}$ in 6 -well cluster dishes, and incubated in a humidified incubator at $37^{\circ} \mathrm{C}$ with $95 \%$ air and $5 \% \mathrm{CO}_{2}$. The cells were divided into a control group, model group (treated with cerulein) and resistin treatment group (treated with cerulein and resistin). The drugs were dissolved in PBS and added at the following concentrations: $100 \mathrm{nM}$ cerulein (Sigma-Aldrich; Merck Millipore, Darmstadt, Germany) and $8 \mathrm{nM}$ resistin (ProSpecTany TechnoGene, Ltd., Rehovot, Israel). In a previous study, it was found that resistin exhibits maximal effects on pancreatic acinar cells at a concentration of $8 \mathrm{nM}$ (21) and this concentration is also close to the levels of resistin in patients with AP on admission (19). For the treatment groups, the cells $\left(1 \times 10^{5}\right.$ cells/ $\mathrm{ml})$ were pre-treated with resistin at $37^{\circ} \mathrm{C}$ for $30 \mathrm{~min}$ prior to the addition of cerulein. AR42J cells treated with PBS alone were used as negative controls. After $24 \mathrm{~h}$, the cells and culture media were harvested for further analysis. To determine the effect of NF- $\kappa \mathrm{B}, \mathrm{AR} 42 \mathrm{~J}$ cells were incubated for $2 \mathrm{~h}$ at $37^{\circ} \mathrm{C}$ with $60 \mu \mathrm{M}$ pyrrolidine dithiocarbamate (PDTC) (Sigma-Aldrich; Merck Millipore), an antioxidant, which acts as a specific inhibitor of NF- $\kappa$ B activation (25), prior to stimulation with cerulein or resistin.

Estimation of amylase secretion. The culture media was collected and amylase assays were performed. The secretion of amylase was measured using the 2-chloro-4-nitrophenyl- $\alpha-m$ altotrioside method according to the manufacturer's protocols (Kehua Bio, Shanghai, China). Absorbance data were measured at $405 \mathrm{~nm}$, and amylase secretion was expressed in units per liter using the standard curve provided by the manufacturer.

Total RNA isolation and reverse transcription-quantitative polymerase chain reaction $(R T-q P C R)$ analysis. Total RNA was isolated from the AR42J cells using TRIzol reagent (Invitrogen; Thermo Fisher Scientific, Inc.). cDNA synthesis was performed using a One Step PrimeScript miRNA cDNA Synthesis kit (Takara Biotechnology Co., Ltd., Dalian, China). Specific mRNA quantification was performed using qPCR analysis using SYBR Premix Ex TaqTM II (Takara Biotechnology Co., Ltd.) in a Lightcycler 480 Real-Time PCR system (Roche Diagnostics, Meylan, France) as previously described (26). The tumor necrosis factor- $\alpha$ (TNF- $\alpha$ ), interleukin (IL)-6 and glyceraldehyde-3-phosphate dehydrogenase (GAPDH) primers were designed using Primer Express 2.0 computer software (Applied Biosystems; Thermo Fisher Scientific, Inc.). The gene-specific primers used were as follows: TNF- $\alpha$, sense 5'-TGAACTTCGGGGTGATCG-3' and antisense 5'-GGGCTTGTCACTCGAGTTTT-3'; IL-6, sense 5'-TCGAGCCCACCAGGAACGAAAGT-3' and antisense 5'-AGTAGGGAAGGCAGTGGCTGTCA-3'; GAPDH, sense 5'-CTCAACTACATGGTCTACATGTTCCA-3' and antisense: 5'-CTTCCCATTCTCAGCCTTGACT-3'. All reactions involved initial denaturation at $95^{\circ} \mathrm{C}$ for $5 \mathrm{~min}$, followed by 40 cycles of $95^{\circ} \mathrm{C}$ for $10 \mathrm{sec}, 60^{\circ} \mathrm{C}$ for $20 \mathrm{sec}$ and $79^{\circ} \mathrm{C}$ for $20 \mathrm{sec}$. The $\mathrm{Cq}$ value was defined as the number of PCR cycles in which the fluorescence signal exceeded the detection threshold value. First, $\Delta \mathrm{Cq}=\mathrm{Cq}$ Gene-Cq GAPDH. Then, $\Delta \Delta \mathrm{Cq}=\Delta \mathrm{Cq}$ treated $-\Delta \mathrm{Cq}$ control. Lastly, $2^{\Delta \Delta \mathrm{Cq}}$ was calculated to represent the relative mRNA expression of target genes (27). The relative quantity of $\mathrm{mRNA}$ for each gene was normalized based on that of the housekeeping gene, GAPDH.

Western blot analysis. Variations in the protein expression levels of the NF- $\kappa$ B p65 subunit in the nuclei of AR42J cells were detected using western blot analysis. Cell lysates and nuclear extracts were prepared using a Nuclear and Cytoplasmic Protein Extraction kit (Beyotime Intitute of Biotecnology, Nantong, China) according to the manufacturer's protocols. The proteins were quantified using a BCA Protein Assay kit (Beyotime Intitute of Biotecnology). For the western blot assays, equal quantities of the protein samples (18 $\mu \mathrm{l})$ were separated by $10 \%$ SDS-PAGE, following which they were electrophoretically transferred onto PVDF membranes (Invitrogen; Thermo Fisher Scientific, Inc.). The non-specific sites on each blot were blocked for $1 \mathrm{~h}$ at room temperature with $5 \%$ milk powder diluted in TBS with $0.05 \%$ Tween-20 (TBST). The membranes were then incubated with the following antibodies: Rabbit polyclonal anti-NF- $\kappa$ B p65 (diluted 1:1,000; Abcam, Cambridge, MA, USA) and mouse monoclonal anti-lamin-B (diluted 1:1,000; Santa Cruz Biotechnology, Inc., Santa Cruz, CA, USA). Following incubation at $4^{\circ} \mathrm{C}$ overnight with primary antibodies, the blots were washed four times with TBST buffer. The blots were then finally incubated with horseradish peroxidase (HRP)-conjugated goat anti-rabbit secondary antibodies (1:10,000; Santa Cruz Biotechnology, Inc.) and HRP-conjugated goat anti-mouse secondary antibodies (1:1,000; Santa Cruz Biotechnology, Inc.) at room temperature for $2 \mathrm{~h}$. The proteins were detected using an enhanced chemiluminescence reagent (Pierce; Thermo Fisher Scientific, Inc.). Band intensity was quantified using Bandscan 5.0 software (Glyko, Novato, CA, USA). Protein expression was normalized to lamin B.

Statistical analysis. All statistical analyses were performed using SPSS version 12.0 (SPSS, Inc., Chicago, CA, USA). Data are expressed as the mean \pm standard deviation of three independent experiments performed in duplicate. Statistical significance was evaluated using one-way analysis of variance with Student-Newman-Keuls test for post hoc analysis. $\mathrm{P}<0.05$ was considered to indicate a statistically significant difference. 


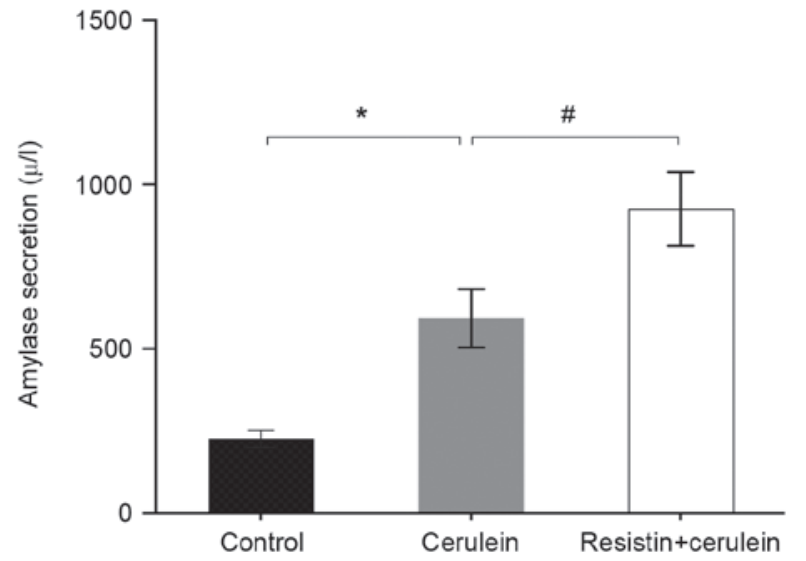

Figure 1. Amylase secretion in AR42J cells. AR42J cells were incubated with cerulein alone or with resistin, and amylase secretion was examined. The data are presented as the mean \pm standard deviation of three independent experiments, each performed in duplicate. ${ }^{*} \mathrm{P}<0.01 ;{ }^{*} \mathrm{P}<0.05$.

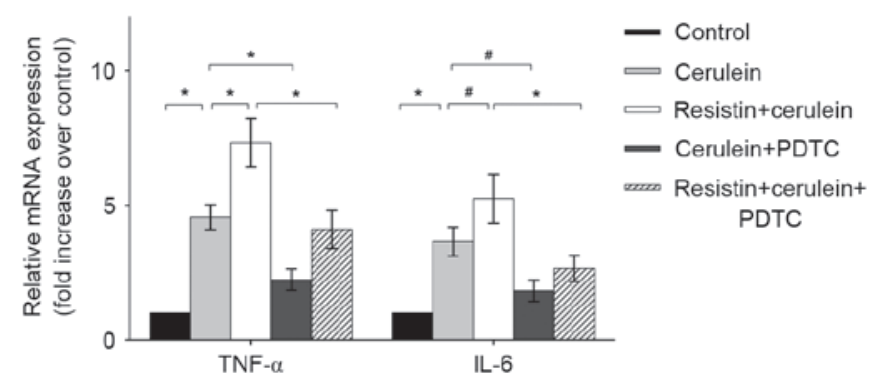

Figure 2. mRNA expression of TNF- $\alpha$ and IL-6 in AR42J cells. AR42J cells were incubated with or without the NF- $\kappa$ B inhibitor, PDTC, for $2 \mathrm{~h}$, followed by stimulation with cerulein or cerulein+resistin. Total RNA was extracted from the AR42J cells and assayed for the mRNA expression of TNF- $\alpha$ and IL-6 using reverse transcription-quantitative polymerase chain reaction analysis. GAPDH was used as an internal control. The data are presented as the mean \pm standard deviation of three independent experiments, each performed in duplicate. ${ }^{*} \mathrm{P}<0.01 ;{ }^{\#} \mathrm{P}<0.05$. TNF- $\alpha$, tumor necrosis factor $\alpha$; IL-6, interleukin-6; NF-кB, nuclear factor kappa B; PDTC, pyrrolidine dithiocarbamate; GAPDH, glyceraldehyde-3-phosphate dehydrogenase.

\section{Results}

Effects of resistin on amylase secretion in cerulein-treated AR42J cells. Treatment of the AR42J cells with cerulein increased the secretion of amylase into the culture media, compared with the untreated control cells $(\mathrm{P}<0.01$; Fig. 1$)$. In the resistin-pretreated in vitro AP model, a significantly higher concentration of amylase secretion was produced, compared with that in the cerulein-treated group ( $\mathrm{P}<0.05$; Fig. 1).

Effects of resistin on the $m R N A$ expression of proinflammatory cytokines in cerulein-treated AR42J cells. The results of the RT-qPCR analysis demonstrated that the mRNA expression levels of TNF- $\alpha$ and IL- 6 in the cerulein-treated group were increased significantly, compared with the levels observed in the untreated controls ( $\mathrm{P}<0.01$; Fig. 2). Resistin treatment augmented the increased mRNA levels of TNF- $\alpha$ and IL- 6 mRNA elicited by cerulein (TNF- $\alpha, \mathrm{P}<0.01$; IL-6, $\mathrm{P}<0.05$; Fig. 2). Notably, pretreatment of cells with PDTC significantly attenuated the mRNA expression levels of TNF- $\alpha$ and IL-6

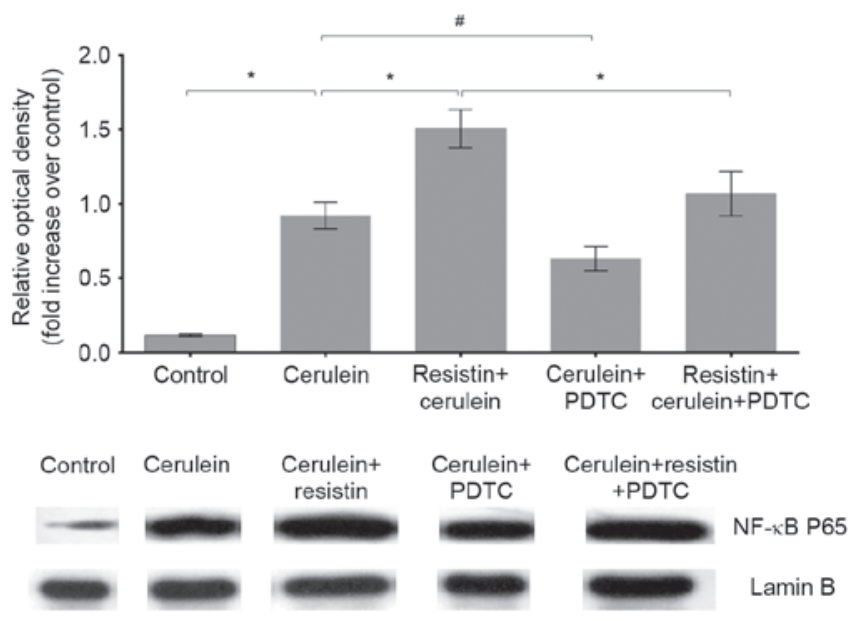

Figure 3. Western blot analysis of protein levels of the NF- $\kappa \mathrm{B}$ p65 subunit in the nuclear fraction of AR42J cells. AR42J cells were incubated with or without NF- $\kappa$ B inhibitor PDTC for $2 \mathrm{~h}$, followed by stimulation with cerulein or cerulein+resistin. Subsequently, cells were subjected to nuclear extraction to detect protein levels of the NF- $\mathrm{B}$ p 65 subunit. Protein expression was normalized to lamin $\mathrm{B}$. The data are presented as the mean \pm standard deviation of three independent experiments, each performed in duplicate. ${ }^{*} \mathrm{P}<0.01$ and ${ }^{\#} \mathrm{P}<0.05$. NF- $\kappa \mathrm{B}$, nuclear factor $-\kappa \mathrm{B}$; PDTC, pyrrolidine dithiocarbamate.

in the resistin+cerulein-treated group $(\mathrm{P}<0.01$; Fig. 2$)$ and the cerulein-treated group (TNF- $\alpha, \mathrm{P}<0.01$; IL-6, P<0.05; Fig. 2).

Effects of resistin on the protein levels of $N F-\kappa B$ p65 in the nuclei of cerulein-treated AR42J cells. Cerulein treatment significantly increased the protein levels of the NF- $\kappa \mathrm{B}$ p65 subunit in the nuclei of the AR42J cells, compared with the untreated controls $(\mathrm{P}<0.01$; Fig. 3). Resistin treatment augmented the increase in the protein level of $\mathrm{NF}-\kappa \mathrm{B}$ p65 elicited by cerulein $(\mathrm{P}<0.01$; Fig. 3). PDTC pretreatment significantly recovered the protein levels of $N F-\kappa B$ p 65 in the cerulein+resistin-treated group $(\mathrm{P}<0.01$; Fig. 3$)$ and cerulein-treated group $(\mathrm{P}<0.05$; Fig. 3).

\section{Discussion}

The present study aimed to investigate the functional consequences of exposing rat pancreatic acinar cells to resistin and to determine whether it amplifies proinflammatory signaling in an in vitro AP model. Treatment of the AR42J cells with cerulein, which induced the secretion of amylase and mRNA expression levels of TNF- $\alpha$ and IL-6, led to the successful development of the in vitro model of AP. Pancreatic AR42J cells are derived from acinar cells and are the only currently available cell line that maintains normal pancreatic acinar cell characteristics (28). The expression of AR42J cell receptor and signal transduction mechanisms have been demonstrated to parallel the mechanisms found in human pancreatic acinar cells (29). Therefore, these cells are now widely applied in investigations of cellular secretion, growth, proliferation and apoptosis of the exocrine pancreas (30).

In the present study, pretreatment with resistin augmented the secretion of amylase and the expression levels of proinflammatory molecules in the in vitro model of AP. These findings correlate well with clinical observations suggesting the validity of reports linking the clinical severity and 
outcomes of AP with circulating levels of resistin $(17,19)$. Daniel et al (18) also demonstrated that the levels of resistin may provide a useful tool for the prognosis and monitoring of AP. Resistin is widely considered to be an obesity-associated adipocytokine, based on numerous studies, which have demonstrated high circulating levels of resistin in obese rodents and are associated with several pathological conditions $(16,31,32)$. The novel feature of resistin as a proinflammatory molecule has been acknowledged. Several studies have reported that resistin can trigger a proinflammatory state $(16,22,33,34)$. Silswal et al (35) incubated macrophages with recombinant resistin and found that the production of TNF- $\alpha$ and IL-12 increased. The exposure of hepatic stellate cells to resistin has been also found to result in increased expression levels of monocyte chemoattractant protein-1 and IL-8 (36). In our previous study, it was demonstrated that resistin treatment was capable of inducing the expression of TNF- $\alpha$ and IL-6 in pancreatic acinar cells (21).

Inflammation is the hallmark of human and experimental pancreatitis (37). It is well known that proinflammatory responses occurring subsequent to acinar cell injury can determine the ultimate severity of the resulting pancreatitis. Elevated TNF- $\alpha$ and IL- 6 have been reported to be correlated with disease severity in patients with AP (38). Preventing the expression of TNF- $\alpha$ attenuates the stress response and leads to decreases in the mortality rates of patients with AP (39). The overexpression of IL- 6 has been shown to increase susceptibility to AP (40). In the present study, the augmented expression of inflammatory cytokines induced by resistin exposure in the AP model led to an increase in the severity of injury to pancreatic acinar cells, which contributed evidence to the previously reported association between obesity and increased severity in patients with AP (39).

$\mathrm{NF}-\kappa \mathrm{B}$ has the ability to upregulate the expression of inflammatory molecules induced in experimental pancreatitis models (41). The present study further investigated the role of $\mathrm{NF}-\kappa \mathrm{B}$ inflammatory response augmentation induced by resistin in an in vitro model of AP. It was shown that the increasing production of proinflammatory cytokines was accompanied by NF- $\kappa \mathrm{B}$ activation. Pretreatment with the NF- $\kappa \mathrm{B}$ inhibitor, PDTC, completely attenuated the production of proinflammatory cytokines induced by resistin in the in vitro AP model. This suggested that the effect of resistin on augmenting the inflammatory response in the AP model was specifically dependent on $N F-\kappa B$ activation. This finding is consistent with previous studies, demonstrating that $\mathrm{NF}-\kappa \mathrm{B}$ activation is a key mediator of the inflammatory response in patients with AP $(24,41,42)$.

In conclusion, the results of the present study showed that resistin amplified the expression of proinflammatory cytokines via the $\mathrm{NF}-\kappa \mathrm{B}$ pathway in the cerulein-induced in vitro AP model. These preliminary indications suggested that the overproduction of obesity-associated resistin and associated inflammatory response may result in aggravation of the severity of AP. However, further investigations are required for future application of these findings in humans.

\section{Acknowledgements}

The present study was supported by a grant from the National Natural Science Foundation of China (grant no. 30901433).

\section{References}

1. Ogden CL, Carroll MD, Kit BK and Flegal KM: Prevalence of childhood and adult obesity in the United States, 2011-2012. Jama 311: 806-814, 2014.

2. Abu Hilal M and Armstrong T: The impact of obesity on the course and outcome of acute pancreatitis. Obes Surg 18: 326-328, 2008.

3. Chen SM, Xiong GS and Wu SM: Is obesity an indicator of complications and mortality in acute pancreatitis? An updated meta-analysis. J Dig Dis 13: 244-251, 2012.

4. Sadr-Azodi O, Orsini N, Andrén-Sandberg A and Wolk A: Abdominal and total adiposity and the risk of acute pancreatitis: A population-based prospective cohort study. Am J Gastroenterol 108: 133-139, 2013.

5. Premkumar R, Phillips AR, Petrov MS and Windsor JA: The clinical relevance of obesity in acute pancreatitis: Targeted systematic reviews. Pancreatology 15: 25-33, 2015.

6. Acharya C, Navina S and Singh VP: Role of pancreatic fat in the outcomes of pancreatitis. Pancreatology 14: 403-408, 2014.

7. Martínez J, Johnson CD, Sánchez-Paya J, de Madaria E, Robles-Diaz G and Perez-Mateo M: Obesity is a definitive risk factor of severity and mortality in acute pancreatitis: An updated meta-analysis. Pancreatology 6: 206-209, 2006.

8. Hong S, Qiwen B, Ying J, Wei A and Chaoyang T: Body mass index and the risk and prognosis of acute pancreatitis: A meta-analysis. Eur J Gastroenterol Hepatol 23: 1136-1143, 2011.

9. Johnson CD, Toh SK and Campbell MJ: Combination of APACHE-II score and an obesity score (APACHE-O) for the prediction of severe acute pancreatitis. Pancreatology 4: 1-6, 2004.

10. Grundy SM: Adipose tissue and metabolic syndrome: too much, too little or neither. Eur J Clin Invest 45: 1209-1217, 2015.

11. Vazquez-Vela ME, Torres N and Tovar AR: White adipose tissue as endocrine organ and its role in obesity. Arch Med Res 39: 715-728, 2008.

12. Cao H: Adipocytokines in obesity and metabolic disease. J Endocrinol 220: T47-T59, 2014.

13. Steppan CM, Bailey ST, Bhat S, Brown EJ, Banerjee RR, Wright CM, Patel HR, Ahima RS and Lazar MA: The hormone resistin links obesity to diabetes. Nature 409: 307-312, 2001.

14. Bokarewa M, Nagaev I, Dahlberg L, Smith U and Tarkowski A: Resistin, an adipokine with potent proinflammatory properties. J Immunol 174: 5789-5795, 2005.

15. Qatanani M, Szwergold NR, Greaves DR, Ahima RS and Lazar MA: Macrophage-derived human resistin exacerbates adipose tissue inflammation and insulin resistance in mice. J Clin Invest 119: 531-539, 2009.

16. Jamaluddin MS, Weakley SM, Yao Q and Chen C: Resistin: functional roles and therapeutic considerations for cardiovascular disease. Br J Pharmacol 165: 622-632, 2012.

17. Daniel P, Leśniowski B, Jasińska A, Pietruczuk M and Malecka-Panas E: Usefulness of assessing circulating levels of resistin, ghrelin, and IL-18 in alcoholic acute pancreatitis. Dig Dis Sci 55: 2982-2987, 2010.

18. Daniel P, Leśniowski B, Mokrowiecka A, Jasińska A, Pietruczuk $M$ and Małecka-Panas E: Circulating levels of visfatin, resistin and pro-inflammatory cytokine interleukin- 8 in acute pancreatitis. Pancreatology 10: 477-482, 2010.

19. Schäffler A, Hamer O, Dickopf J, Goetz A, Landfried K, Voelk M, Herfarth H, Kopp A, Büchler C, Schölmerich J and Brünnler T: Admission resistin levels predict peripancreatic necrosis and clinical severity in acute pancreatitis. Am J Gastroenterol 105: 2474-2484, 2010

20. Filková M, Haluzik M, Gay S and Senolt L: The role of resistin as a regulator of inflammation: Implications for various human pathologies. Clin Immunol 133: 157-170, 2009.

21. Jiang CY, Wang W, Tang JX and Yuan ZR: The adipocytokine resistin stimulates the production of proinflammatory cytokines TNF-alpha and IL-6 in pancreatic acinar cells via NF-kappaB activation. J Endocrinol Invest 36: 986-992, 2013.

22. Song YZ, Guan J, Wang HJ, Ma W, Li F, Xu F, Ding LB, Xie L, Liu B, Liu K and Lv Z: Possible involvement of serum and synovial fluid resistin in knee osteoarthritis: Cartilage damage, clinical, and radiological links. J Clin Lab Anal 30: 437-443, 2016.

23. Barnes PJ and Karin M: Nuclear factor-kappaB: A pivotal transcription factor in chronic inflammatory diseases. N Engl J Med 336: 1066-1071, 1997. 
24. Gukovsky I, Li N, Todoric J, Gukovskaya A and Karin M: Inflammation, autophagy, and obesity: Common features in the pathogenesis of pancreatitis and pancreatic cancer. Gastroenterology 144: 1199-1209e1194, 2013.

25. Schreck RMB, Männel DN, Dröge W and Baeuerle PA: Dithiocarbamates as potent inhibitors of nuclear factor kappa B activation in intact cells. J Exp Med 175: 1181-1194, 1992.

26. Jiang ZY, Jiang CY, Wang L, Wang JC, Zhang SD, Einarsson C, Eriksson M, Han TQ, Parini P and Eggertsen G: Increased NPC1L1 and ACAT2 expression in the jejunal mucosa from Chinese gallstone patients. Biochem Biophy Res Com 379: 49-54, 2009.

27. Livak KJ and Schmittgen TD: Analysis of relative gene expression data using real-time quantitative PCR and the 2(-Delta Delta C(T)) Method. Methods 25: 402-408, 2001.

28. Logsdon CD, Guthrie J, Alves F and Rosewicz S: Glucocorticoids have opposite effects on ornithine decarboxylase and cell growth in pancreatic acinar AR42J cells. Yale J Biol Med 65: 449-456, 465-449, 1992

29. Gonzalez A, Santofimia-Castaño P and Salido GM: Culture of pancreatic AR42J cell for use as a model for acinar cell function. Pancreapedia: Exocrine Pancreas Knowledge Base, 2011.

30. Masamune A, Sakai Y, Satoh A, Fujita M, Yoshida M and Shimosegawa T: Lysophosphatidylcholine induces apoptosis in AR42J cells. Pancreas 22: 75-83, 2001.

31. Ye H, Zhang HJ, Xu A and Hoo RL: Resistin production from adipose tissue is decreased in $\mathrm{db} / \mathrm{db}$ obese mice and is reversed by rosiglitazone. PLoS one 8: e65543, 2013.

32. Elsayed EY, Mosalam NA and Mohamed NR: Resistin and insulin resistance: A link between inflammation and hepatocarcinogenesis. Asian Pac J Cancer Prev 16: 7139-7142, 2015.

33. Al-Daghri N, Chetty R, McTernan PG, Al-Rubean K Al-Attas O, Jones AF and Kumar S: Serum resistin is associated with C-reactive protein \& LDL cholesterol in type 2 diabetes and coronary artery disease in a Saudi population. Cardiovasc Diabetol 4: 10, 2005.
34. Al Hannan F and Culligan KG: Human resistin and the RELM of Inflammation in diabesity. Diabetol Metab Syndr 7: 54, 2015.

35. Silswal N, Singh AK, Aruna B, Mukhopadhyay S, Ghosh S and Ehtesham NZ: Human resistin stimulates the pro-inflammatory cytokines TNF-alpha and IL-12 in macrophages by NF-kappaB-dependent pathway. Biochem Biophys Res Commun 334: 1092-1101, 2005.

36. Bertolani C, Sancho-Bru P, Failli P, Bataller R, Aleffi S, DeFranco R, Mazzinghi B, Romagnani P, Milani S, Ginés P, et al: Resistin as an intrahepatic cytokine: Overexpression during chronic injury and induction of proinflammatory actions in hepatic stellate cells. Am J Pathol 169: 2042-2053, 2006.

37. Cohen MC and Cohen S: Cytokine function: A study in biologic diversity. Am J Clin Pathol 105: 589-598, 1996.

38. Bhatia M: Inflammatory response on the pancreatic acinar cell injury. Scand J Surg 94: 97-102, 2005.

39. Sunden-Cullberg J, Nyström T, Lee ML, Mullins GE, Tokics L, Andersson J, Norrby-Teglund A and Treutiger CJ: Pronounced elevation of resistin correlates with severity of disease in severe sepsis and septic shock. Crit Care Med 35: 1536-1542, 2007.

40. Suzuki S, Miyasaka K, Jimi A and Funakoshi A: Induction of acute pancreatitis by cerulein in human IL-6 gene transgenic mice. Pancreas 21: 86-92, 2000.

41. Rakonczay Z Jr, Hegyi P, Takács T, McCarroll J and Saluja AK: The role of NF-kappaB activation in the pathogenesis of acute pancreatitis. Gut 57: 259-267, 2008.

42. Chen X, Ji B, Han B, Ernst SA, Simeone D and Logsdon CD: NF-kappaB activation in pancreas induces pancreatic and systemic inflammatory response. Gastroenterology 122: 448-457, 2002. 